\title{
A natureza do trabalho intelectual humano segundo Dietzgen
}

\author{
Bruce Robinson \\ Pesquisador em Sistemas de Informação e Sociedade \\ (Universidade de Salford - Inglaterra) \\ bruce@,brucerob.eu
}

Versão original da resenha publicada em 27 fev. 2011. Disponível em:
http://marxandphilosophy.org.uk/reviewofbooks/reviews/2011/276

TRADUÇÃO:

José Carlos Mendonça

Doutorando em Ciências Sociais (Universidade Estadual de Campinas - UNICAMP)

Pesquisador do Laboratório de Sociologia do Trabalho (LASTRO - UFSC)

josecarlos@cfh.ufsc.br

Pablo Mizraji

Graduando em Ciências Sociais (Universidade Federal de Santa Catarina - UFSC)

pmizraji@gmail.com

DIETZGEN, Joseph. A Natureza do Trabalho Intelectual Humano: Uma Introdução à Dialética. Oakland (EUA): PM Press, 2010, 142 p.

DIETZGEN, Joseph. The Nature of Human Brain Work: An Introduction to Dialectics.

PM Press, Oakland, 2010. 142 p., ISBN 9781604860368.

Originais recebidos em: 08/08/2011

Aceito para publicação em: 02/09/2011

\section{(c) (1) $9 \Theta$} Atribuição-Uso Não-Comercial-Vedada a criação de obras derivadas 3.0 Unported License. 
Em setembro de 1868 Joseph Dietzgen, um curtidor mestre autodidata da Renânia, enviou um manuscrito a Karl Marx sobre a "faculdade de pensar" perguntando sobre a possibilidade de publicá-lo. No ano seguinte, apareceu Nature of Human Brain Work - Uma Crítica Renovada da Razão Pura e Prática (NHBW), agora disponibilizada novamente na tradução original em Inglês de 1906 por Ernst Untermann com um esboço biográfico de Larry Garbone.

Dietzgen, que há muito tempo considerou-se um seguidor de Marx, tinha se inspirado a escrever um trabalho sobre a base do pensamento humano e do conhecimento tanto por seu "desejo de uma concepção coerente e sistemática do mundo" quanto pela crença política de que somente a classe trabalhadora poderia compreender o mundo independentemente dos restritos interesses de classe.

Hoje geralmente Dietzgen é uma figura esquecida no marxismo. Foi caracterizado de todas as formas: de positivista e empirista a precursor do marxismo ocidental, de materialista inconsistente a um suplemento necessário para Marx, portanto, pode-se concluir que Dietzgen foi um filósofo desafortunadamente inconsistente. De fato, ao se ler Dietzgen como um todo coerente, se nem sempre ele se expressou consistentemente, um conjunto de idéias surge. NHBW é a sua primeira formulação.

Dietzgen começa por discutir a natureza da filosofia, contrastando-a com a ciência. A Filosofia especulativa desenvolve a razão do próprio pensamento sem referência ao material, ao mundo experimentado pelos sentidos. Como a ciência avançou, o domínio da especulação diminuiu e, se a filosofia é a mais geral das ciências, tem que preocupar-se não com especulações ociosas, mas com "explicar[ndo] a natureza geral do processo de pensamento" (p. 16). Ao mesmo tempo, Dietzgen rejeita uma alternativa contemporânea ao idealismo na Alemanha, o materialismo reducionista de Büchner, Vogt e Moleschott. Ele reconhece que "o pensamento é uma função do cérebro e do sistema nervoso central como a escrita é uma função da mão. Mas o estudo da anatomia da mão não pode mais resolver a questão: O que é escrever? que o estudo da fisiologia do cérebro pode nos aproximar da solução da questão: O que é o pensamento?” (p. 17) O pensamento tem de ser explicado em termos de faculdades mentais, em vez de função do cérebro (daí o "trabalho do cérebro" no título talvez seja melhor traduzido como "trabalho mental").

Dietzgen baseia a sua análise sobre uma ontologia monista em que o mundo é um todo interligado, que é apenas a forma mais abstrata e geral de existência. Todos os 
nossos pensamentos apenas se relacionam com as partes desse todo e são definidos em um contexto particular: "Perfeitamente verdade, perfeitamente universal é apenas a existência em geral, o universo ... Mas o mundo real é absolutamente relativo, absolutamente perecível. Todas as verdades são simplesmente partes do mundo, verdades parciais." (p. 42)

Não há nada, nenhuma "coisa em si” incognoscível se escondendo atrás das manifestações da existência em geral que experimentamos através dos nossos sentidos. "Fenômenos aparecem, isso é tudo." (p. 36) O conhecimento nunca é completo, mas não tem limites a priori.

A partir daí, Dietzgen deriva uma dialética na qual “os opostos são mutuamente relativos" (p. 43), isto é, interdependentes e contextualmente fluidos, e investiga pares como verdade e erro, matéria e mente, causa e efeito, parte e todo, e meios e fins. No entanto, na ocasião, Dietzgen embaça as distinções importantes, afirmando a identidade dos dois conceitos, quando eles têm uma relação mais complexa.

O pensamento tem então por objeto, sem o qual não poderia existir, impressões dos sentidos levadas à mente pela "passagem de múltiplas manifestações da natureza e da vida". (p. 43) No entanto, elas não se limitam a definir o conteúdo do pensamento como alegado por aqueles que acusam Dietzgen de ter uma "teoria do reflexo" da consciência. Em vez disso, elas são a "matéria-prima para nossa atividade cerebral." (p. 36) O pensamento tem um papel ativo na formação do material fornecido aos sentidos em formas de pensamento. Especificamente, o pensamento abstrai da infinidade de interconexões o seu objeto e generaliza a partir da percepção imediata e individual dos sentidos (o "concreto") em categorias que utiliza para fins de compreensão (o "geral"). Diferentes abstrações e generalizações são possíveis a partir de um determinado conjunto de impressões sensoriais. Dietzgen não aborda diretamente a questão de como surgem e são partilhados os conceitos científicos, mas aponta para o papel do método científico para distinguir a verdade do erro e nota de passagem que "a ciência é uma questão social tanto quanto a produção material" (p. 5-6) e que a "verdade da teoria se manifesta na prática” (p. 36, 5).

Para Dietzgen, as impressões dos sentidos não são apenas o que é fisicamente palpável, audível, etc forças imperceptíveis, tais como gravidade, magnetismo e energia elétrica também são materiais. Mas Dietzgen de modo mais controverso afirma que "a idéia de intangível é também material e real. Eu percebo a minha idéia de uma mesa tão claramente quanto a própria mesa [...] Se houver objecções à palavra "material"”, Em Debat: Rev. Dig., ISSNe 1980-3532, Florianópolis, n. 6, p. 258-263, jul-dez, 2011. 
continua ele, "podemos chamar de mente real, tão real como a mesa palpável, a luz visível, como o som audível.” (p. 18-19)

O pensamento pode, portanto, ser tomado como seu próprio objeto, e isso cria a possibilidade da filosofia especulativa se separar das impressões sensoriais. Este movimento levou Lenin (1972) a acusar Dietzgen de fazer concessões ao idealismo, mas em vez disso ele está buscando explicar como o idealismo se manifesta. Esta concepção do pensamento como real também fornece um importante corretivo para os materialistas vulgares e empiristas. "O idealista considera a razão como a fonte de todo o entendimento, enquanto o materialista olha para o mundo das impressões dos sentidos da mesma maneira. Não se exige solução para esta contradição, mas a compreensão da interdependência relativa entre essas duas fontes de entendimento.” (p. 69)

A transformação das impressões dos sentidos em formas de pensamento permite Dietzgen chegar a uma unidade em que o pensamento é, simultaneamente, ativo na ordenação do mundo e criador de nossas ideias quando baseadas em uma realidade material. Mais tarde, isto levaria Dietzgen a cunhar o termo "materialismo dialético" para descrever sua filosofia.

Nos dois últimos capítulos de NHBW Dietzgen usa essa visão de mundo como base para formular uma crítica na áreas das ciências naturais e da ética e da moralidade. Ele critica os cientistas que, uma vez que se desviam para fora de seu próprio campo científico, tornam-se presas de todo tipo de erros filosóficos. Ele faz isso examinando dialeticamente as três relações entre matéria e mente, causa e efeito e força e matéria.

Dietzgen, procura contextualizar as idéias apresentadas como verdades morais eternas. Aqui ele se vale do método materialista histórico, subordinando a moralidade às necessidades humanas expressas de formas diferentes em diferentes épocas e contextos e, assim, chega a uma definição de classe da moralidade: "o nobre russo considera a servidão uma instituição racional do mesmo modo que o burguês inglês a assim chamada liberdade de seu trabalhador assalariado, essas duas instituições não são absolutamente racionais, mas apenas relativamente a um círculo mais ou menos limitado." (p. 84) A base de uma falsa moralidade eterna consiste em tomar estas formas históricas como absolutas. De modo semelhante Dietzgen deduz uma compreensão dialética de fins e meios, afirmando aqui que Ollman (2003) atribui a Dietzgen a autoria de uma filosofia das relações internas: "As coisas são o que são somente no seu interior e por suas interrelações. As circunstâncias alteram os casos.” (p. 97) 
NHBW é o primeiro trabalho que pode ser genericamente chamado de filosofia marxista não escrito por Marx e Engels. Em uma citação que mais tarde tornou-se famosa, Engels (1990) apresentou Dietzgen como tendo descoberto a "dialética materialista ... independentemente de nós" (citação não totalmente exata - Dietzgen tinha conhecimento de alguns escritos de Marx e tinha identificado elementos filosóficos em “O Capital”). Marx (1988) observou em NHBW a forte influência de Feuerbach, com quem Dietzgen se correspondeu. Dietzgen afirmou não ter lido Hegel, o que Marx considerou uma debilidade dentre "tanta coisa excelente" em NHBW. Sua explicação dos processos de conceituação é, deste ponto de vista, incompleta. Embora seu ponto de partida seja semelhante ao de Hegel, sua dialética não forma um sistema e ignora algumas categorias importantes para a dialética de Marx. Assim, NHBW talvez indique as possibilidades e limites de uma filosofia marxista baseada em Feuerbach, ao invés de Hegel.

As idéias de Dietzgen por vezes são expressas em uma prosa um tanto desajeitada e ele se repete em alguns momentos. No entanto NHBW deve ser lida, primeiramente pelo seu significado como o pensamento de um marxista precursor, o primeiro a desenvolver idéias filosóficas e chegar a um entendimento independente, que era ao mesmo tempo dialético e materialista. Mas é mais do que interesse meramente histórico. Há várias idéias em NHBW que são importantes em si mesmas. Em primeiro lugar, o monismo dialético de Dietzgen o capacitou a desenvolver uma teoria do conhecimento que ele usou para atacar a idéia de que há aspectos do mundo que são incognoscíveis. Mais tarde, ele a usou para criticar a emergente escola neo-kantiana, na Alemanha. Em segundo lugar, sua insistência sobre a necessidade de uma teoria da mente, bem como dos pontos de atividade cerebral como necessários para uma psicologia crítica, num momento em que a disciplina nem sequer existia. Sua afirmação da materialidade do pensamento sustenta isso e permite-lhe dar uma explicação materialista para o pensamento especulativo. Finalmente, a explicação de Dietzgen sobre os processos de abstração e generalização na formação de conceitos continua a ser de ampla aplicação. 60 anos depois encontra eco na conceitualização de Vygotsky (1986) e tem sido aplicado hoje em campos tão diferentes como a Marxologia (Ollman, 2003) e sistemas de informação (Robinson, 1997).

A republicação de NHBW é bem-vinda e esperamos que possa levar a um renascimento do interesse pelos escritos de Dietzgen, poucos dos quais estão disponíveis hoje. 


\section{Referências bibliográficas}

Engels, F. 1990. Ludwig Feuerbach and the End of Classical German Philosophy. In: Marx and Engels: Collected Works, Vol. 26. (London: Lawrence and Wishart)

Marx, K. and Engels, F. 1988. Letters 1868-70. Marx and Engels: Collected Works, Vol. 43. (London: Lawrence and Wishart)

Lenin, V.I. 1972. Materialism and Empirio-Criticism, In: Collected Works, Vol. 14. (Moscow: Progress Publishers)

Ollman, B. 2003. Dance of the Dialectic (Urbana: University of Illinois Press)

Robinson, B. 1998. Dialectics and Modelling in Information Systems. Systemist, 20, 208-220.

Vygotsky, L.S. 1986. Thought and Language (Cambridge: MIT Press). 